\title{
Correction to: Evaluation of periodontal status and cytokine/ chemokine profile of GCF in patients with severe congenital neutropenia
}

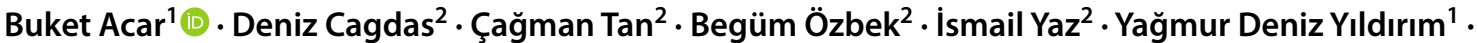 Cansu Özşin-Özler ${ }^{3}$ - Betül Karaatmaca ${ }^{2}$ Pınar Gür-Çetinkaya ${ }^{2} \cdot$ Elif Soyak $^{2} \cdot$ Erdem Karabulut $^{4}$. Illhan Tezcan ${ }^{2}$. Ezel Berker ${ }^{1}$}

Published online: 30 December 2020

(c) The Society of The Nippon Dental University 2020

\section{Correction to: Odontology \\ https://doi.org/10.1007/s10266-020-00565-1}

In the original publication of the article, second author's name was published incorrectly as "Deniz Çağdaş Ayvaz". The correct name is "Deniz Cagdas".

The original article has been corrected.

Publisher's Note Springer Nature remains neutral with regard to jurisdictional claims in published maps and institutional affiliations.

The original article can be found online at https://doi.org/10.1007/ s10266-020-00565-1.

Buket Acar

dtbuketonder@gmail.com

1 Department of Periodontology, Faculty of Dentistry, Hacettepe University, Ankara 06230, Turkey

2 Department of Pediatric Immunology, Faculty of Medicine, Hacettepe University, Ankara, Turkey

3 Department of Pediatric Dentistry, Faculty of Dentistry, Hacettepe University, Ankara, Turkey

4 Department of Biostatistics, Faculty of Medicine, Hacettepe University, Ankara, Turkey 